\title{
DO NATURALISMO AO MODERNISMO: AS EXPERIÊNCIAS TEATRAIS DE SÁ-CARNEIRO E FERNANDO PESSOA E A TENTATIVA DE RENOVAÇÃO DO DRAMA PORTUGUÊS
}

\author{
Isabelle Regina de Amorim-Mesquita ${ }^{1}$
}

RESUMO: Este artigo analisa o teatro português dos primeiros anos do século XX a partir de reflexões sobre peças de Sá-Carneiro e Fernando Pessoa. No Primeiro Modernismo, a forma dramática está em crise: de um lado, ela está ainda bastante vinculada aos moldes tradicionais do Naturalismo e, de outro, tenta renovar a sua estrutura com experiências dramáticas inovadoras.

PALAVRAS-CHAVE: Teatro; Fernando Pessoa; Sá-Carneiro.

ABSTRACT: This paper offers an analysis of Portuguese drama in the first years of the $20^{\text {th }}$ century from a reflection on Sá-Carneiro's and Fernando Pessoa's plays. In the First Modernism Movement, the dramatic form is in crisis: on one hand it is still linked to the traditional models of Naturalism and, on the other hand, it tries to renew its structure with innovative dramatic experiences.

KEYWORDS: Drama; Fernando Pessoa; Sá-Carneiro.

Os artistas portugueses do início do século XX revolucionaram os conceitos de poesia e prosa. Com as inventivas do Orpheu, os dois gêneros foram os que mais sofreram transformações com a absorção do ideário órfico e abandonaram os pressupostos oitocentistas em favor de uma nova maneira de se fazer arte. No plano do teatro, entretanto, o Primeiro Modernismo não causou a mesma renovação estética como, sem dúvida, ocorreu com o poema e a narrativa. Os palcos portugueses ainda eram tomados por obras de cunho naturalista, as quais estavam muito presas aos padrões mais tradicionais do teatro.

O teatro português do século XIX está associado à concepção de mundo de uma nova classe social que toma o poder: a burguesia. Com um aumento expressivo do público consumidor do teatro, o número de salas de espetáculo se multiplicou pelos centros culturais portugueses e peças passaram a ser encenadas em grande escala. Contudo, conforme comenta Rebello (1978), essa aceleração no ambiente teatral não contribuiu para a melhora da qualidade literária das peças. A falta de intelectualidade do público burguês foi o principal motivo pelo qual o teatro em Portugal não atingiu os mesmos níveis de modernização e renovação estéticas já vivenciadas pelos outros gêneros artísticos. $\mathrm{O}$ autor argumenta: 
${ }^{1}$ Doutoranda em Estudos Literários, pela Faculdade de Ciências e Letras da UNESP, e bolsista CAPES. Email: isabelleamorim@yahoo.com.br

O teatro tornava-se assim uma espécie de feudo exclusivo de uma classe privilegiada, para a qual funcionava, não como [...] 'uma curiosidade do espírito', mas como 'um ócio de sociedade'. Para essa minoria desprovida de exigências, ou sequer de curiosidades, intelectuais, 'actores sem estudo, sem escola, sem incentivos, sem ordenados, sem público', [...] representavam más traduções e imitações do repertório francês, muitas vezes anunciadas como originais, que seguiam invariavelmente um de três modelos fixos: 'o drama sentimental e bem escrito, de belas imagens, ode dialogada em que uma personagem lança frases soberbamente floridas, a outra retruca em períodos sonoros e melódicos, e a acção torna-se assim um tiroteio de prosas ajanotadas'; o 'drama de efeito, com o que se chama finais de acto, lances bruscos, um embuçado que aparece, uma mãe que se revela'; e 'a farsa com os velhos motivos de pilhéria lusitana, o empurrão, o tombo, a matrona bulhenta, o general de barrete de dormir' (REBELLO, 1978, p. 24-5).

Como se pode notar, o drama oitocentista em Portugal está pautado na caricatura. Os personagens são representados de forma cômica e não há uma preocupação em se pensar criticamente os conflitos íntimos dos seres e nem mesmo os costumes da época. Essa tendência dramática perdurou fortemente por todo o século XIX e alcançou também os anos iniciais do século XX, perfazendo um atraso estético do teatro português se comparado ao que se vinha produzindo nos demais países da Europa. Marca expressiva desse atraso é que em Portugal o Realismo não se manifestou no teatro. De acordo ainda com Rebello:

não houve entre nós verdadeiramente, e por via de regra, uma dramaturgia realista - mas, quando muito, naturalista. Os escritores teatrais portugueses que intentaram trasladar para o palco a realidade que os seus sentidos apreendiam e lhes estimulava a imaginação, contentavam-se em fotografá-la, abstendo-se de a interpretar e mais ainda de concorrer para transformá-la. (REBELLO, 1978, p. 56).

Inspirados pelos textos de Zola e pelos dramas de Ibsen e Strindberg, as primeiras obras teatrais naturalistas só surgiram em Portugal no final do século, com a publicação de Os Velhos (1893), de D. João da Câmara, e de A Imaculável (1897), de Abel Botelho. Entretanto, esse foi o momento que surgiram já as primeiras tentativas de teatro simbolista, como, por exemplo, O Pântano (1894), também de D. João da Câmara. 
A exemplo do que ocorre na obra de Câmara, no drama português do final do século XIX coexistem várias correntes estéticas, como o historicismo (herança romântica), a comédia de costumes, o Naturalismo e o Simbolismo, contudo, conforme lembra Cruz (1983), dentro da heterogeneidade de estilos e formas, o Naturalismo vai preponderar nos primeiros anos do século XX:

$\mathrm{O}$ naturalismo encontra no início do século $\mathrm{XX}$ português razões poderosas de inspiração. O ambiente é-lhe propício, pois a crise de mudança de regime, e, de uma maneira geral, toda a restante teoria de fenómenos político-sociais, determina uma inquietação que o teatro soube reproduzir. (CRUZ, 1983, p. 137).

Influenciado pela mudança de regime político e pela instauração da República, o drama naturalista em Portugal preocupa-se, fundamentalmente, com a representação da sociedade e dos sujeitos que nela vivem. Problemas de ordem política, social e científica são investigados pelo olhar do dramaturgo de forma a retratar o mais fielmente possível a relação do indivíduo com o meio e a preocupação com o destino imposto pelas leis da hereditariedade. Neste aspecto, a verossimilhança é um dos recursos estéticos mais trabalhados pelos autores do período. Com isso, no plano temático, o teatro naturalista pauta-se em uma problemática social e a ação dramática situa-se essencialmente em fatos do cotidiano burguês.

No que toca às questões estilísticas e formais, o drama naturalista defende os pressupostos mais tradicionais do gênero. Quanto ao enredo, por exemplo, ele tem como base uma linha narrativa a ser desenvolvida de maneira lógica e sequencial; as ações são coesas e seguem em direção a um conflito a ser necessariamente resolvido.

A respeito da elaboração dos personagens, o teatro naturalista também respeita as noções tradicionais: são apresentadas geralmente figuras-tipos que representam um papel na sociedade. A caracterização de tais seres é feita de maneira exterior, na medida em que seus atributos físicos, sua inserção no ambiente familiar e social são definidores de suas atitudes e valores (não há, portanto, uma grande preocupação com o psicologismo das figuras dramáticas).

O diálogo é outro fundamento deste drama; sem ele a ação não se desenvolve e a intriga não é resolvida. O monólogo e o silêncio dramático não são explorados, tendo 
em vista que tais recursos podem parecer inverossímeis aos olhos dos dramaturgos (e espectadores) tão preocupados com a aproximação máxima com a realidade.

A linguagem deste drama de características tradicionais é simples e bem próxima da fala coloquial, haja vista que deve ser um veículo facilitador da compreensão da obra pelo público burguês.

No que toca à montagem, é interessante destacar, ainda, que tanto o cenário como a maquiagem e mesmo o vestuário dos atores possuem um caráter artificial. Numa tentativa de reprodução fiel do real, os objetos em cena são muitas vezes pintados, a maquiagem dos artistas é exagerada e suas roupas servem para reforçar a caracterização dos sujeitos enquanto entes sociais.

Como dissemos, este tipo de drama tradicional invade os palcos portugueses já no século XX, ficando aquém das renovações estéticas experimentadas pela narrativa e pela poesia. Um caso típico é o do autor Mário de Sá-Carneiro. Engajado com os pressupostos inovadores do Modernismo da geração do Orpheu, o autor elabora poemas e textos em prosa com uma proposta estética inovadora e bem diferente daquela trabalhada pelos seus antecessores; contudo, o teatro de Sá-Carneiro, na contramão de sua produção mais conhecida, ainda está bastante vinculado à estética naturalista.

A peça Amizade (1912), escrita em parceria com Tomás Cabreira Júnior, é a primeira produção dramática publicada do autor. Dividida em três atos e estes em um grande número de cenas, a peça inicia-se com uma epígrafe de Zola, a qual sugere que toda relação entre um homem e uma mulher fatalmente tende para a posse carnal. Tal epígrafe já anuncia o motivo da peça: a amizade entre pessoas de sexo oposto acaba, inevitavelmente, sendo tomada pelos desejos da carne.

A temática desenvolvida é, com isso, a questão do destino que envolve uma família sofredora dos mais sérios problemas que possam afetar uma geração familiar: o adultério e o incesto.

Toda a ação da peça se desenvolve numa propriedade rural burguesa, que é detalhada pela rubrica inicial:

Uma vasta sala. Decorações de cores sombrias. Ao centro um bufete de pau-santo; à esquerda um piano. As portas necessárias e, ao fundo, uma mais ampla dando para um jardim. Nos primeiros dias de maio. Manhã de sol. - A ação decorre numa propriedade, a vivenda do Dr. 
Afonso da Silveira, situada nos arredores de Lisboa. Atualidade. (SÁCARNEIRO, 1995, p. 635).

Neste ambiente vivem os concunhados Afonso e Raquel e seus respectivos filhos: Ricardo e Maria. Os dois jovens primos almejam se casar em breve e o assunto que motiva a trama é o casamento deles.

O primeiro ato da peça vem apresentar os integrantes da cena: membros de uma família tradicional burguesa, os personagens vivem num ambiente afastado dos centros urbanos e, em meio aos preparativos para o casamento de seus filhos, recebem uma visita inesperada: Cesário - um pintor, velho conhecido da família que chega de Paris e se hospeda na vivenda. Com a chegada deste personagem e por meio do diálogo entre ele, Afonso e Raquel, o passado da família começa a ser relembrado.

É válido notar que as cenas se quebram quando as figuras mais velhas comentam algo do passado familiar e, no mesmo instante, chega um dos jovens noivos. Tal estratégia discursiva vem contribuir para a promoção do mistério, elemento recorrente nas peças oitocentistas.

Também característico dos dramas naturalistas é a existência de um escândalo familiar. Neste caso, pela conversa entre os mais velhos, sabe-se que a família em questão é marcada por uma fatalidade: Afonso e Raquel perdem seus respectivos cônjuges de maneira trágica. A esposa de Afonso morre e este se aproxima mais de seu irmão, marido de Raquel, indo morar com eles. Em uma viagem a trabalho, o irmão de Afonso morre tragicamente e, com isso, Afonso resolve fugir dos comentários que envolvem um possível relacionamento com a cunhada e muda-se para um lugar afastado levando Raquel, a sobrinha e o filho, ainda pequenos.

Durante o segundo ato, a ação centra-se no casal de jovens. Criados juntos desde crianças, seus pais fazem questão que eles se casem. Maria aprendeu a cuidar da casa, a cozinhar, enfim, foi criada para ser uma boa esposa e prendada dona-de-casa. Já Ricardo concentra-se nos estudos. Ele espera concluir logo a faculdade de medicina para poder ter condições de se casar.

Nas vésperas do casamento, Maria nota que as atitudes de seu noivo estão um tanto estranhas: ele a esquiva e não é mais atencioso e carinhoso como antes. A moça chora e queixa-se para a mãe. Ricardo, por sua vez, acaba por confessar ao pai que recebera uma carta anônima que o deixou extremamente perturbado. O recebimento de 
tal carta acaba por romper com a harmonia em que vivia a família. Um dos momentos de maior tensão da peça é quando Afonso comenta o conteúdo da correspondência à Raquel:

A sua confiança e a sua boa-fé é que não podem conceber uma tal aleivosia... Ah! Mas desengana-se, ela existe! Prevenções traiçoeiras... cartas anônimas a informá-lo de que nós somos amantes... de que as nossas relações datam de há longos anos... de que já existiam em vida de meu irmão... Foi por isso mesmo que ele fugiu para o Brasil... foi só essa a causa da sua morte... Numa palavra: afirmam que o casamento dos nossos filhos seria um sacrilégio... um incesto talvez! (SÁ-CARNEIRO, 1995, p. 664).

O terceiro ato é marcado pela desestabilização no ambiente familiar: Afonso e Raquel juram que são apenas amigos, que o conteúdo da carta é falso; Ricardo, por outro lado, pega um revólver e pensa em se matar, contudo, a fraqueza física o vence, já que o rapaz adoece. Maria, por sua vez, a garota que parecia frágil e alienada de tudo tendo em vista que a todo instante choramingava pelos cantos e somente pensava em se casar - nota que entre a sua mãe e seu tio existe algo além da amizade. Ela confidencia a Cesário que desconfia do amor dos dois e como o amigo confirma as suas dúvidas, Maria pede a ele que ajude na realização deste amor proibido.

Num primeiro instante Afonso e Raquel relutam em assumir seus sentimentos, visto que se preocupam com o preconceito que possam sofrer. Todavia, Cesário argumenta que agora as suas almas ultrapassaram os limites da amizade, que neste momento o amor dos corpos fala mais alto e conclui:

[...] o vosso enlace, repito, é a única solução possível. Não julguem que falo por amor da moral, dessa moral tola de convenções e de parvoeiras. Foi coisa que nunca me importou. $\mathrm{O}$ caso é outro: é que vocês têm filhos, um homem e uma mulher, que perceberiam imediatamente o que se passava entre os dois. Não há nada como as situações claras, e isso não seria uma situação clara. Demais, se é a forma como esse ato pode ser interpretado pelos outros que os aterroriza - que diabo! - vão viver todos para o estrangeiro; saiam deste país onde nada os prende, onde nunca foram felizes. Não se deve fazer caso do 'mundo', no entanto a sua voz incomoda como o uivar dum cão. Afastem-se pois dele e, sossegados e satisfeitos consigo próprios, gozarão duma ventura perdurável, livre de todas as nuvens, que foi coisa que vocês nunca conheceram: a vossa felicidade foi sempre ou interminante ou sombreada... Eis o que devem fazer e o que hão-de fazer! (SÁ-CARNEIRO, 1995, p. 677-8). 
A resolução do conflito é patética. Cesário sugere uma nova fuga para o casal para que estes não sofram mais uma vez com o repúdio da sociedade. Ambos aceitam o conselho e a peça termina com o planejamento dos casamentos de Afonso e Raquel e de Ricardo e Maria, os quais terão Cesário como padrinho.

A grande tensão dramática embasada pela dúvida a respeito do adultério e do incesto é minimizada, no desfecho da peça, em favor de um final feliz para os personagens, conforme conclui Cesário na fala que encerra o texto: "Minha filha, pela primeira vez, uma carta anônima fez a felicidade dum lar!...” (SÁ-CARNEIRO, 1995, p. 679).

Como podemos notar, este texto dramático de Mário de Sá-Carneiro ainda está bastante preso aos pressupostos da estética naturalista. Tanto a temática como as unidades de tempo, ação e a própria construção linguística e dos personagens seguem um modelo tradicional de teatro que predominou durante o século XIX e que continua a resistir mesmo em autores tão inovadores do século XX.

$\mathrm{O}$ teatro português do princípio do século $\mathrm{XX}$, se comparado aos demais gêneros, encontra-se, como dissemos, atrasado esteticamente, tendo em vista que a poesia e a narrativa já estão em processo de renovação, acompanhando as novas tendências vanguardistas européias. Durante este período, o drama começa a enfrentar um momento de crise e, para se superar e se estabelecer novamente como um gênero produtivo, vai precisar experimentar novas formas.

O drama estático de Fernando Pessoa é um exemplo das primeiras modificações que o gênero sofre em decorrência da crise da forma dramática que compreende o final do século XIX. O marinheiro representa um período de transição do teatro naturalista para o teatro de vanguarda, o qual finalmente consegue renovar a já desgastada forma dramática oitocentista e se firmar como teatro do Modernismo.

Peter Szondi, em sua Teoria do drama moderno (2001), comenta que o drama europeu do período Renascentista até os finais do século XIX mantém uma forma específica baseada, essencialmente, em quatro categorias: o diálogo intersubjetivo e as unidades de ação, tempo e espaço.

Apesar da constante mudança temática que envolvia os períodos artísticos em questão, a forma dramática permanecia praticamente imutável ao longo dos séculos. 
Entretanto, ainda segundo Szondi, durante o século XX o drama desenvolve o seu esquema estrutural com a inserção de elementos épicos no seio da forma dramática tradicional, o que gera, em meados do século, o estabelecimento de uma nova forma para o drama, cunhada por Brecht como o teatro épico.

A evolução do drama de sua forma tradicional para a moderna não ocorre bruscamente, tendo em vista que os experimentalismos formais começam a ser praticados durante a passagem do século XIX para o XX quando os dramaturgos europeus passam a pensar a estrutura dramática associada ao conteúdo temático das peças.

A forma e o conteúdo não são tomados mais separadamente, conforme ocorria desde o Classicismo. Com o avanço da ciência, da tecnologia e do surgimento dos primeiros estudos freudianos, novos temas ganharam a atenção dos dramaturgos e, acompanhando tamanha variedade temática, a forma dramática - agora indissociável de seu conteúdo - passa a sofrer algumas alterações em suas quatro categorias fundamentais.

Este momento de reflexão sobre o drama é denominado por Szondi como “crise". Para ele, os dramaturgos do período de transição do século XIX para o XX iniciam um processo de modificação da forma dramática tradicional para que o drama possa, também por meio de sua estrutura, refletir melhor sobre os novos temas que preocupam o homem.

A crise do drama é sentida ainda durante o Naturalismo, contudo, segundo Szondi, este período artístico está bastante vinculado à estética dramática tradicional:

O naturalismo, por mais que tenha se portado de modo revolucionário e tenha querido sê-lo inclusive no estilo e na "visão de mundo", tomou na dramaturgia uma direção conservadora. No fundo importava-lhe preservar a forma do drama tradicional. (SZONDI, 2001, p. 54-5).

A partir do Naturalismo há um expressivo aumento do questionamento sobre a forma dramática e, portanto, a crise do drama se intensifica. Em Portugal, contudo, os primeiros exercícios formais ocorrem mais sistematicamente somente no início do século XX. A peça $O$ marinheiro, de Fernando Pessoa, é uma das que mais se identificam com o momento de crise da forma dramática. Para entendermos um pouco 
mais como o drama reage às transformações, analisaremos brevemente o texto pessoano.

A peça $O$ marinheiro - escrita em 1913 e publicada pela primeira vez em 1915, na revista Orpheu - está cronologicamente inserida nas propostas do Primeiro Modernismo português. Subintitulada como "drama estático em um quadro", o texto dramático já a partir de seu título e subtítulo apresenta, de forma indireta, alguns questionamentos sobre a tradição dramática.

A começar, é válido destacar que o marinheiro - figura que intitula a peça não é um personagem que aparece em cena, já que apenas surge no sonho de uma das personagens. O ente central da trama dramática só existe na imaginação, fazendo com que o estatuto de personagem do drama oitocentista seja quebrado. Além disso, ao contrário do drama tradicional, nenhuma personagem é nomeada e nem caracterizada em detalhes.

No que toca ao subtítulo do texto, ele mostra que a peça também não segue os modelos mais tradicionais de configuração teatral, tendo em vista que ao invés de dividido em atos, o texto possui apenas um quadro, o qual é determinado como “estático". De fato, em $O$ marinheiro não existe uma ação a se desenvolver, os personagens em cena não se movem em momento algum e toda a trama está centrada no diálogo de tais figuras.

A peça é aberta com a seguinte rubrica:

Um quarto que é sem dúvida num castelo antigo. Do quarto vêse que é circular. Ao centro ergue-se, sobre uma essa, um caixão com uma donzela, de branco. Quatro tochas aos cantos. À direita, quase em frente a quem imagina o quarto, há uma única janela, alta e estreita, dando para onde só se vê, entre dois montes longínquos, um pequeno espaço de mar.

Do lado da janela velam três donzelas. A primeira está sentada em frente à janela, de costas contra a tocha de cima da direita. As outras duas estão sentadas uma de cada lado da janela.

É noite e há como que um resto vago de luar. (PESSOA, 1979, p. 35).

O espaço cênico é fechado, escuro, característico do momento fúnebre que celebram as três veladoras. Há apenas uma janela ao fundo, de onde se vê o mar. As três figuras em cena são as únicas que passam a noite ao lado do caixão da donzela. Para 
quebrar o silencio entristecedor, a primeira veladora sugere que conversem sobre o passado: "sempre é belo falar do passado" (PESSOA, 1979, p. 36).

Como se pode notar, o passado é o tema da peça. Ele é presentificado pela memória e pelos sonhos das veladoras que pouco comentam sobre a sorte da moça que velam. Pelo contrário, tomadas pelas suas reminiscências mais subjetivas, elas renunciam o presente em favor do sonho. A preferência pelo passado e pelo sonho rompe com a ideia de fidelização do real e do momento presente tão explorados pelo drama naturalista, o que comprova, mais uma vez, uma crise na forma dramática existente no drama português do início do século $\mathrm{XX}$ e uma tentativa de renovação estética para o teatro.

A busca pelo sonho reflete, ainda, uma insatisfação com o presente. As veladoras praticamente ignoram o caixão e os ritos funerais e são tomadas pelo encantamento do mar que é visto em curta extensão pela janela. Com a vista do horizonte, as veladoras imaginam um marinheiro que tem proporções de um personagem real. A segunda veladora comenta:

Sonhava de um marinheiro que se houvesse perdido numa ilha longínqua. Nessa ilha havia palmeiras hirtas, poucas, e aves vagas passavam por elas... Não vi se alguma vez pousavam... Desde que, naufragado, se salvara, o marinheiro vivia ali... Como ele não tinha meio de voltar à pátria, e cada vez que se lembrava dela sofria, pôs-se a sonhar uma pátria que nunca tivesse tido; pôs-se a fazer ter sido sua uma outra pátria, uma outra espécie de país com outras espécies de paisagens, e outra gente, e outro feitio de passarem pelas ruas e de se debruçarem das janelas... Cada hora ele construía em sonho esta falsa pátria, e ele nunca deixava de sonhar, de dia à sombra curta das grandes palmeiras, que se recortava, orlada de bicos, no chão areento e quente; de noite, estendido na praia, de costas e não reparando nas estrelas. (PESSOA, 1979, p. 46-7).

As três veladoras se envolvem profundamente com a história do marinheiro. Para as personagens, ele tem vida e é mais real do que elas próprias, que são tomadas pelas lembranças do passado, são solitárias e não encontram uma razão concreta para viver.

As três figuras femininas, consumidas pelo sonho, perdem as suas individualidades. Suas falas chegam a se confundir, como se elas fossem desdobramentos de um único personagem. 
O diálogo - reflexo da relação íntima das veladoras - é a todo instante interrompido por pausas, que são explicitadas textualmente pela rubrica e pelo grande número de reticências que aparece, sem exceção, em todas as réplicas das figuras femininas.

O silêncio acaba consumindo a cena dramática e é motivo de pavor para os personagens. A primeira veladora, desesperadamente, tenta romper com o silêncio que invade também o íntimo de sua existência:

[...] Ah, falemos, minhas irmãs, falemos alto, falemos todas juntas... O silêncio começa a tomar corpo, começa a ser cousa... Sinto-o envolver-me como uma névoa... Ah, falai, falai!... (PESSOA, 1979, p. 39).

A falta de regularidade das réplicas e tréplicas, as pausas e os silêncios contribuem para que o diálogo, constituído pelas divagações das irmãs, se torne a expressão de uma única voz angustiada com o presente e que vive à custa de um sonho. Com isso, as três vozes se juntam, numa expressão bem próxima ao monólogo.

A linguagem do monólogo não tem a finalidade de comunicar, mas, na peça, serve como uma manifestação dos sentimentos e do desenvolvimento psíquico dos personagens. Deste modo, a linguagem de $O$ marinheiro se distancia de sua concepção mais tradicional e própria do drama (que é a comunicação) para se aproximar da lírica.

A recusa ao diálogo e à ação reflete a recusa da própria forma dramática, colocada em cheque por $O$ marinheiro. Outra categoria dramática questionada pela peça é a unidade de ação, tendo em vista que nada acontece em cena, não há movimentação dos personagens e a obra não se baseia na progressão de uma intriga; ao contrário, tudo o que se passa envolve o psicologismo das irmãs.

Assim como a ação dramática, o tempo também não é bem sistematizado pela peça. Sabe-se que a cena ocorre numa madrugada, mas os personagens perdem a noção da passagem do tempo em meio às suas fantasias: “[...] Ah, mas porque é que falamos? Quem é que nos faz continuar falando? Porque falo eu sem querer falar? Porque é que já não reparamos que é dia?..." (PESSOA, 1979, p. 57).

Como se pode notar, a peça $O$ marinheiro promove um debate sobre a tradição dramática, questionando as formas cristalizadas do drama naturalista. $\mathrm{Na}$ peça de 
Pessoa, o drama é o reflexo da crise de uma forma que não atende mais aos anseios expressos pela temática.

Atento à necessidade de renovação modernista para o teatro português, Fernando Pessoa, com a peça $O$ marinheiro, abre os caminhos para que o drama do início do século XX abandone os ideários estéticos oitocentistas mais tradicionais - que ainda vigoravam em Portugal - em favor de uma arte de vanguarda. Seu companheiro de geração Almada Negreiros é o integrante do grupo que seguirá a proposta inovadora experimentada por Pessoa e exercitará o gênero com ousadia, fazendo com que o teatro em Portugal acompanhe as tendências vanguardistas do Modernismo.

\section{Referências Bibliográficas}

REBELLO, L. F. O teatro naturalista e neo-romântico (1970-1910). Lisboa: Instituto de Cultura Portuguesa, 1978.

CRUZ, D. I. Introdução ao teatro português do século XX. Lisboa: Guimarães editores, 1983.

SÁ-CARNEIRO, M. Teatro. In: . Obra completa: volume único. Introdução e organização de Alexei Bueno. Rio de Janeiro: Nova Aguilar, 1995, p. 631-95.

SZONDI, P. Teoria do drama moderno: 1880-1950. Trad. Luiz Sérgio Rêpa. São Paulo: Cosac \& Naify Edições, 2001. Título original: Theorie des modernen Dramas 18801950.

PESSOA, F. O marinheiro. In: Poemas dramáticos. $1^{\circ}$. Volume. Lisboa: Ática, 1979 , p. 31-63. 